J. Lake Sci. (湖泊科学), 2021, 33(3): 842-853

DOI 10. 18307/2021. 0317

(C) 2021 by Journal of Lake Sciences

\title{
鄱阳湖洪泛区碟形湖湿地系统地表一地下水交互作用”
}

\author{
陈 静 $^{1,2}$, 李云良 ${ }^{3 * *}$, 周俊锋 ${ }^{1}$, 卢静媛 ${ }^{1}$, 韦 丽 $^{1}$, 郭王银 ${ }^{4}$ \\ ( 1 : 江西省水文局, 南昌 330002$)$ \\ (2:河海大学水文水资源学院与水利工程科学国家重点实验室,南京 210098) \\ (3: 中国科学院南京地理与湖泊研究所, 流域地理学重点实验室, 南京 210008) \\ (4:江西省鄱阳湖水文局,九江 332800$)$
}

\begin{abstract}
摘 要: 洪泛系统具有复杂动态的水文环境,在季节性洪水脉冲影响下,地表一地下水交互转化对洪泛区水循环和生态 环境保护等方面具有重要意义. 本文采用野外试验、统计分析和达西定律等研究方法, 开展了鄱阳湖洪泛区碟形湖湿地 系统 (河流一洲滩湿地一碟形湖) 地表一地下水文学特征、相互作用和交换通量研究. 数据资料显示, 在地形地貌影响下, 研 究区洲滩地下水位明显低于碟形湖水位, 但总体上略高于周边河流水位, 统计结果进一步表明, 在控制洪泛湿地的地下 水动态方面, 河流水文情势变化对地下水的影响作用要强于碟形湖水文变化. 就河流一地下水转化关系而言, 研究区湿地 系统的地下水与周边河流水体之间存在动态转化关系, 地下水对河流的补给通量以及河流对地下水的补给通量分别约 为 0.4 和 $0.2 \mathrm{~m} / \mathrm{d}$. 就湖泊一地下水转化关系而言,碟形湖一般来说补给周边滩地的地下水系统,但两者之间的交换通量基 本小于 $0.1 \mathrm{~m} / \mathrm{d}$. 在年尺度上, 研究区地表一地下水之间的累积交换通量变化约介于 $7.5 \sim 48.2 \mathrm{~m} / \mathrm{a}$, 其中河流一地下水的累 积交换通量约是碟形湖一地下水的 4 7 倍,且秋、冬季的累积交换通量要明显大于春、夏季. 本文研究结果可为洪泛区河 湖系统的水资源联合管理、水环境整治和生态环境保护等方面提供科学支撑.
\end{abstract}

关键词: 洪泛水文;碟形湖湿地;交换通量;河湖系统;地表一地下水转化;鄱阳湖

\section{Assessing surface water-groundwater interactions in the seasonal lake-wetland system of Lake Poyang *}

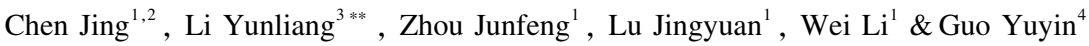

(1: Hydrological Bureau of Jiangxi Province, Nanchang 330002, P.R. China)

(2: State Key Laboratory of Hydrology-Water Resources and Hydraulic Engineering, Hohai University, Nanjing 210098 , P.R. China)

(3: Key Laboratory of Watershed Geographic Sciences, Nanjing Institute of Geography and Limnology, Chinese Academy of Sciences, Nanjing 210008, P.R.China)

(4: Hydrological Bureau of Poyang Lake, Jiangxi Province, Jiujiang 332800, P.R.China)

Abstract: Floodplain systems are affected by seasonal shifts between dry and wet cycles, and therefore cause marked changes in surface water and groundwater flow regimes. Surface water-groundwater interactions are rarely investigated in large floodplain systems, where few surface and groundwater data are obtained or monitored. This study used field observations, statistical analysis, and Darcy's law approach to explore surface water-groundwater dynamics, interactions, and the associated fluxes in a geographically complex river-floodplain wetland-seasonal lake system (Lake Poyang, China). Results indicate that the wetland groundwater is more sensitive to variations in the river levels than the seasonal lakes. Groundwater levels are generally lower than those of the seasonal lakes, but slightly higher than the surrounding river levels, due to the influence of the complex topography. Statistical analysis

* 2020-05-07 收稿;2020-08-31 收修改稿.

国家自然科学基金项目 (42071036，41771037)、江西省水文局青年科技创新基金项目 (SWJJ-KT201904)、江西省 水利厅科技项目 (202022YBKT11) 、河海大学水文水资源与水利工程科学国家重点实验室 “一带一路” 水与可持续 发展科技基金项目 (2020491311) 和中国科学院青年创新促进会项目 (Y9CJH01001) 联合资助.

** 通信作者;E-mail: yunliangli@ niglas.ac.cn. 
further reveals that the river hydrology tends to play a more significant role in controlling groundwater dynamics, relative to the seasonal lakes. Generally, the river shows gaining conditions (i.e., groundwater recharges river) and occasionally losing conditions (i.e., river recharges groundwater) with variable Darcy fluxes by up to 0.4 and $0.2 \mathrm{~m} / \mathrm{d}$, respectively, while the seasonal lakes are more likely to show slightly losing conditions $(<0.1 \mathrm{~m} / \mathrm{d})$. Additionally, the annual accumulated flux rates range from $7.5 \mathrm{~m} / \mathrm{a}$ to $48.2 \mathrm{~m} / \mathrm{a}$ for surface water-groundwater interactions in the floodplain system. The accumulated flux rate for river-groundwater interactions is around four to seven times higher than that of the seasonal lake-groundwater interactions. Also, the accumulated flux in autumn and winter is higher than that of the spring and summer on a seasonal scale. The findings from this study have important implications for improving the understanding of the water resources joint management, water quality, and eco-environmental protection for both the river and the lake.

Keywords: Floodplain hydrology; seasonal wetland; flux rate; river-lake system; surface water-groundwater interaction; Lake Poyang

在全球大多数地形地貌类型中,河流、湖泊与湿地等地表水体往往与周边地下水系统存在着频繁水力 联系 ${ }^{[1]}$. 地表一地下水之间的自然交换作用对它们自身的物理水文过程以及生态方面具有显著影响作 用 $^{[2-3]}$. 在全球气候变化和人类活动的背景下,尤其是极端气候事件以及强人类活动的干扰, 均在不同程度 上影响着地表水资源和地下水资源的转化和利用,因此导致地表一地下水交互作用的探索与评估成为一个 极为重要且具有实际意义的研究工作 ${ }^{[4]}$.

多年来, 地表水和地下水相互作用的重要性已取得共识, 得到大量研究成果和一些普适性的研究结论. 为应对快速变化的环境, 从水资源联合管理的角度, 对两者相互作用的认识程度需要加强 ${ }^{[5]}$. 随着技术手段 的提升,学者们使用了很多方法来研究地表一地下水交换作用与动力学过程,主要有水位梯度测量法、温度 示踪法、数值模型法、同位素示踪法以及上述两个或多个方法的组合应用 ${ }^{[6-10]}$. 然而, 不同的研究方法几乎均 受到空间、时间尺度以及一些潜在假设的限制, 这些不确定性主要是由水流运动路径的扰动、小尺度空间异 质性和测量装置的设计所限等诸多因素造成的 ${ }^{[11]}$.

洪泛区通常视为一种特殊的湿地类型,受周边浅水湖泊或河流水文情势的影响,具有季节性明显的干 湿交替特征, 其作为全球重要的水文地貌单元之一, 与周边地表一地下水系统有着不可忽视的水力联系. 水 文情势的周期性变化促进了洪泛湿地的地表一地下水相互作用 ${ }^{[12]}$, 进而对有效保护和管理湿地水资源分 配、栖息地生态环境等具有重要意义. 通常情况下,地表一地下水相互作用为湿地生态系统提供了物质、能量 和脉冲输人, 造成湿地诸多生态环境指标的时空高度异质与迁移转化. 因此, 分析洪泛湿地系统中地下水和 地表水之间的交互转化与动力学机制尤为重要, 这决定了湿地的物理性质和生态功能. 因洪泛区下垫面具 有空间异质性程度较高、系统开放性较强、水文节律高度动态等特点,相关的地表一地下水研究仍较为少见.

长江中下游的鄱阳湖洪泛湿地, 是国际公认的重要湿地系统, 在保护生物多样性和生态功能等诸多方 面发挥着不可替代的作用 ${ }^{[13]}$. 由于气候变化和人类活动的双重影响, 湖泊水位的天然波动已经发生了显著 变化, 对湖区水文、生态和经济方面带来联动影响与反馈. 近些年来, 鄱阳湖洪泛湿地的水文变化已经引起 了国家和地方相关部门的高度重视 ${ }^{[14-15]}$, 但主要是以河湖等地表水文水动力过程为主. 随着研究的不断深 人, 前期已有研究强调了地表一地下水动力转化在影响土壤水分、植被分布和养分输送方面的重要性. 文献 调研发现, $\mathrm{Xu}$ 等 ${ }^{[16]}$ 通过鄱阳湖洪泛湿地典型断面的水文一植被联合调查, 基于数据分析发现地下水位和土 壤水分梯度共同影响了湿地植被群落的分布特征, 体现了地下水的贡献作用. 一些学者采用水文学、水化学 等方法对鄱阳湖洪泛湿地的地下水动态进行了探索性研究, 证实了鄱阳湖水文情势变化对洪泛区地下水蓄 量具有动态调节作用 ${ }^{[17]}$, 受资料和方法所限, 基本仍以定性分析与评估为主. 此外, Zhang 等 ${ }^{[18]}$ 利用氢氧稳 定同位素示踪技术, 调查了鄱阳湖洪泛湿地的土壤一植物一大气连续体 (SPAC) 的水分传输过程, 研究发现 河流与周边洪泛湿地的地下水变化对 SAPC 系统的水流迁移转化有明显促进作用,但没有针对地表一地下 水转化开展实质性的研究. 由此可知, 上述研究尝试探索了鄱阳湖洪泛湿地系统地下水的重要性及其贡献 作用, 但受观测资料系统性、连续性以及研究方法等约束条件的影响, 仍缺乏对地表一地下水交互转化关系 和补排通量方面的深人研究, 从而导致对湖泊湿地水资源分配管理、湿地生态环境保护等方面的诠释还不 够全面. 
鉴于上述背景, 本研究的主要目标是: (1) 依托典型区的选择和野外原位观测数据, 分析鄱阳湖碟形湖 湿地系统地表、地下水文要素的动态变化特征与影响因素; (2) 采用统计学方法, 从系统角度来评估碟形湖、 河流和洲滩地下水之间的水力联系, 探求典型湿地系统地表一地下水之间的转化作用关系; (3) 基于原位试 验和能量守恒方程 (达西定律), 定量揭示碟形湖湿地系统地下水与周边重要地表水体之间的交互转化 通量.

\section{1 研究区概况}

鄱阳湖位于长江中游南岸, 是目前为数不多的、仍与周边河流水系保持天然连通的湖泊之一(图 1). 鄱 阳湖承纳上游流域“五河” 来水, 通过湖区调蓄,在北部汇人长江干流,因此鄱阳湖的水文情势主要受“五 河” 来水和长江水位的季节性变化共同影响. 鄱阳湖高度动态的湖区水位生消变化约介于 $8 \sim 22 \mathrm{~m}$ 之间, 使 得湖泊水体面积在 1000 3000 $\mathrm{km}^{2}$ 范围内随季节发生萎缩和扩张. 鄱阳湖总体上较浅, $85 \%$ 的湖区在洪水季 节水深不足 $6 \mathrm{~m}^{[19]}$. 从水文学上, 鄱阳湖是一个高度动态的大型洪泛系统, 呈现出近 $2000 \mathrm{~km}^{2}$ 的洪泛湿地, 主要由碟形湖群、沟壑水系和大面积滩地构成 ${ }^{[17]}$. 碟形湖主要分布在鄱阳湖洪泛湿地内部, 由水文水动力、 泥沙冲淤以及人为改造等形成的大小不一、形状各异的洼地. 因此,这些浅层洼地通常被称为 “碟形湖” [20]. 洪水期,这些碟形湖与主湖区融为一体, 完全地表水文连通, 形成大湖; 低枯水位期, 这些碟形湖与主湖区脱 离地表水力联系, 相对孤立, 由此形成了“湖中湖” 的独特景观. 碟形湖具有植被生物量大、物种多样性丰富、 候鸟生境优越等生态价值, 在维护湿地生物多样性和生态系统完整性上起到十分重要的作用 ${ }^{[20]}$. 鄱阳湖洪 泛湿地约分布着 100 多个碟形湖, 最大水深一般不超过 $2 \mathrm{~m}$, 总面积约 $800 \mathrm{~km}^{2}$, 在防洪、蓄水和生物多样性 保护方面发挥着重要作用 ${ }^{[21]}$. 在自然状态下, 碟形湖主要接受高水位时期的主湖区人流补给, 秋、冬季节水 位则取决于降水、蒸发和下渗作用等 ${ }^{[20]}$. 考虑到碟形湖的形成原因以及周边地貌类型基本一致, 本研究选 取蚌湖 (湖水位监测 BW) 和沙湖 (湖水位监测 SW) 两个典型碟形湖、修水河流 (水位监测 RW) 及其之间的 洪泛洲滩 (地下水位监测 GW1 GW6) 作为联合研究区 (图 1), 以期能够表征鄱阳湖中大多数碟形湖湿地系 统的地表和地下水文特征.

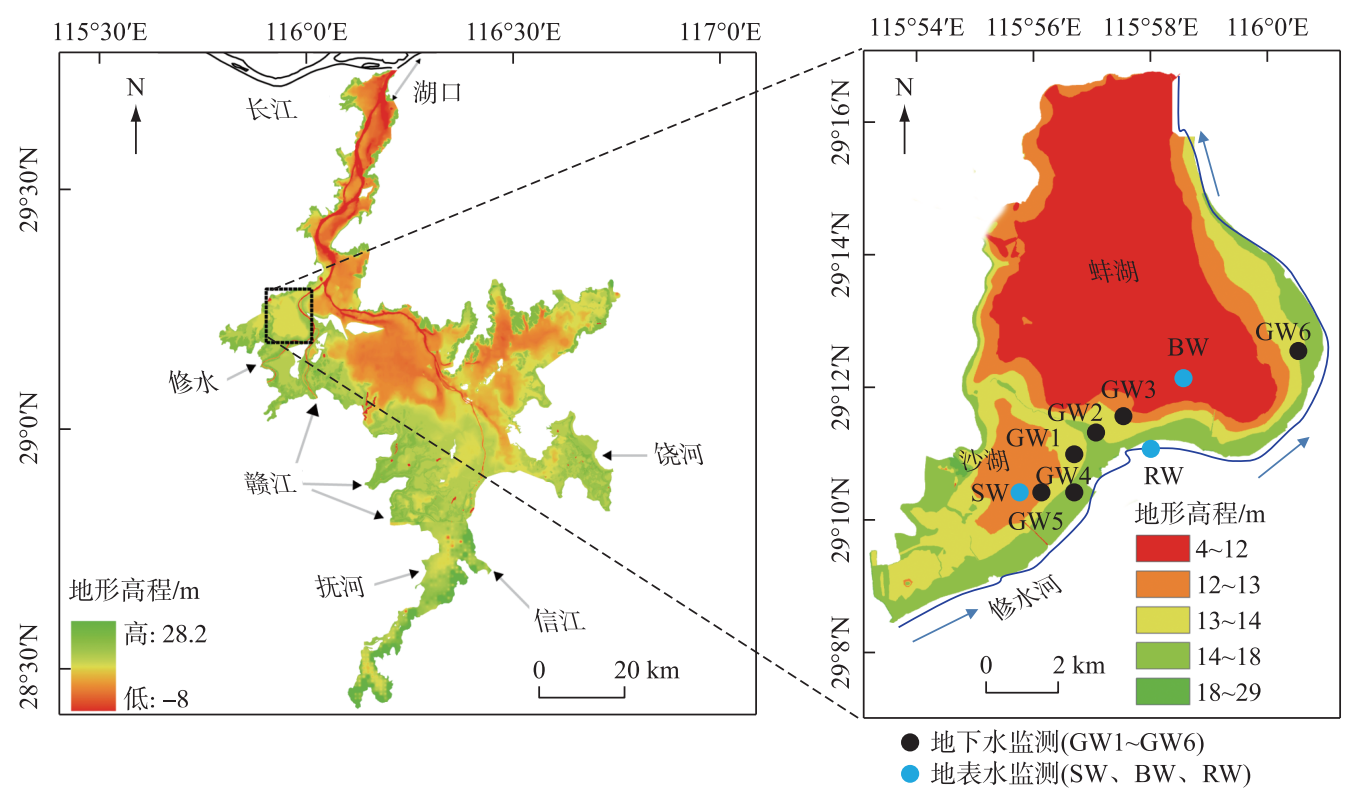

图 1 研究区概况与地表一地下水联合监测示意图

Fig.1 Schematic diagram of the study area and the surface water-groundwater joint monitoring 


\section{2 材料与方法}

\section{1 原位监测和数据获取}

为分析碟形湖湿地的地表一地下水交互作用,需要监测研究区的气象要素、地表水位和地下水位等关键 变量. 气象数据来自中国科学院南京地理与湖泊研究所鄱阳湖湖泊湿地观测研究站(庐山市), 其距离本研 究区大概 $8 \mathrm{~km}$, 用于反映研究区的气象条件变化 (图 2). 为自动监测修水河流、蚌湖和沙湖的水位一水温动 态, 采用加拿大生产的 Solinst 3001 Levelogger 传感器 (水位精度 $0.01 \mathrm{~m}$, 温度精度 $0.05^{\circ} \mathrm{C}$ ), 研究区内共安装 了 3 个传感器 $(R W 、 B W$ 和 $\mathrm{SW}$ ), 将传感器安置在一个直径为 $5 \mathrm{~cm}$ 的铁管中, 并插人河床/湖床底部的沉积 物进行固定. 对于地下水监测, 所有传感器均置于直径为 $5 \mathrm{~cm}$ 的 PVC 管底部, PVC 管底部以上 $1 \mathrm{~m}$ 长度采 用过滤井处理, 确保传感器可用来记录浅层地下水位一水温的完整变化 (GW1 GW6). 为便于数据资料同步 分析, 研究时段选择为 2016 年 1 月 15 日-2017 年 1 月 17 日,覆盖完整的水文周期,数据记录频率为 $1 \mathrm{~h}$.

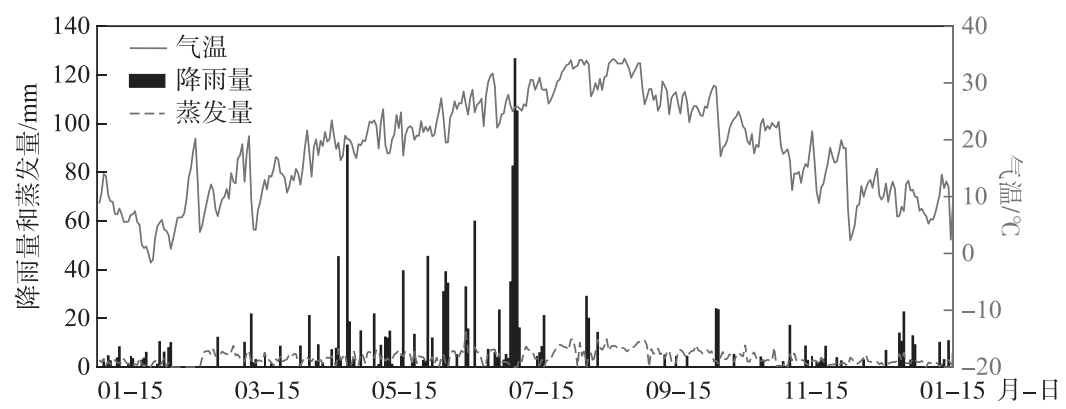

图 2 2016-2017 年星子站主要气象要素的日序列变化

Fig.2 Daily meteorological changes (Xingzi gauging station) in the

Lake Poyang floodplain wetland from 2016 to 2017

为了获取研究区的地质背景信息, 本文采用自然电位和电阻率测井方法, 研究中使用了 ABEM Terramater SAS 4000, 电流电极间距设置为 $3 \mathrm{~m}$, 结合现场实际情况, 对 GW4 和 GW5 之间的东西向剖面开展 了长度约 $400 \mathrm{~m}$ 的地球物理探测, 并通过人工曲线拟合获取了垂向剖面的视电阻率和厚度值. 电阻率分析 表明, 研究区的洪泛洲滩湿地在 $15 \mathrm{~m}$ 的深度范围内可视为均质的 (图 $3 \mathrm{a}$ ). 野外试验和室内分析结果表明, 该深度内主要介质类型为砂层, 粉砂占比较小 (图 3b). 图 3 和表 1 详细描述了洪泛洲滩湿地和各监测点的 地质背景概况.
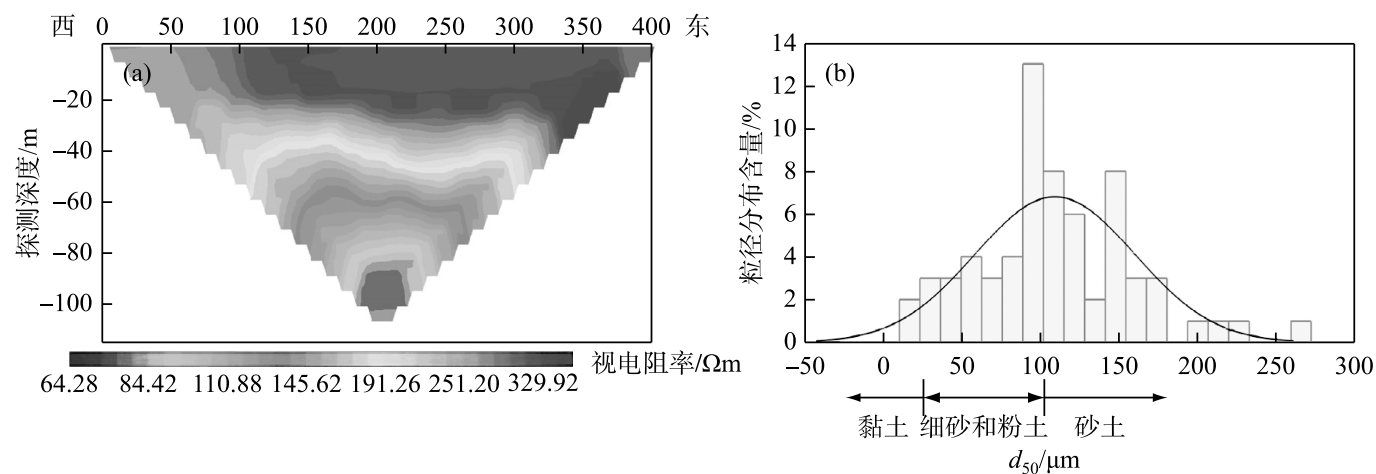

图 3 选择断面的视电阻率 (a) 和基于 66 个采样点的粒径分布 (b) (视电阻率值与含水量变化呈负相关关系)

Fig.3 The apparent resistivity section in the Lake Poyang floodplain wetland (a) and grain-size distribution of average grain size diameter $\left(d_{50}\right)$ with a normal density function for 66 samplings $(\mathrm{b})$

( resistivity values have a negative relationship with underlying water moisture) 
表 1 鄱阳湖洪泛湿地系统地表一地下水监测点位置与地质背景 *

Tab.1 Location and simplified geological setting of monitoring sites within the Lake Poyang floodplain wetland

\begin{tabular}{ccccccc}
\hline 点位 & 观测类型 & 位置坐标 & 高程 $/ \mathrm{m}$ & 深度 $/ \mathrm{m}$ & 过滤井深度 $/ \mathrm{m}$ & 地质信息 \\
\hline $\mathrm{GW} 1$ & 地下水位 & $29.185^{\circ} \mathrm{N}, 115.948^{\circ} \mathrm{E}$ & 13.8 & 12.7 & 12.2 & 细砂 \\
$\mathrm{GW} 2$ & 地下水位 & $29.185^{\circ} \mathrm{N}, 115.948^{\circ} \mathrm{E}$ & 13.7 & 12.5 & 12.0 & 粗砂 \\
$\mathrm{GW} 3$ & 地下水位 & $29.192^{\circ} \mathrm{N}, 115.954^{\circ} \mathrm{E}$ & 13.3 & 10.2 & 9.7 & 细砂 \\
$\mathrm{GW} 4$ & 地下水位 & $29.175^{\circ} \mathrm{N}, 115.950^{\circ} \mathrm{E}$ & 15.0 & 12.1 & 11.6 & 细砂 \\
$\mathrm{GW} 5$ & 地下水位 & $29.207^{\circ} \mathrm{N}, 115.945^{\circ} \mathrm{E}$ & 14.1 & 11.1 & 10.6 & 细砂和粉土 \\
$\mathrm{GW6}$ & 地下水位 & $29.176^{\circ} \mathrm{N}, 116.014^{\circ} \mathrm{E}$ & 14.8 & 14.5 & 14.0 & 细砂 \\
$\mathrm{BW}$ & 蚌湖水位 & $29.198^{\circ} \mathrm{N}, 115.980^{\circ} \mathrm{E}$ & 11.7 & $\mathrm{NA}$ & $\mathrm{NA}$ & 粉土和黏土 \\
$\mathrm{SW}$ & 沙湖水位 & $29.174^{\circ} \mathrm{N}, 115.938^{\circ} \mathrm{E}$ & 13.0 & $\mathrm{NA}$ & $\mathrm{NA}$ & 粉土和秥土 \\
$\mathrm{RW}$ & 修河水位 & $29.183^{\circ} \mathrm{N}, 115.964^{\circ} \mathrm{E}$ & 9.4 & $\mathrm{NA}$ & $\mathrm{NA}$ & 砂和砾石 \\
\hline
\end{tabular}

* NA 表示对于地表水位监测,该项不存在.

\section{2 统计分析}

为分析蚌湖 $(\mathrm{BW})$ 、沙湖 $(\mathrm{SW})$ 、修水 $(\mathrm{RW})$ 等地表水体与洲滩地下水 $(\mathrm{GW} 1 \sim \mathrm{GW} 6)$ 之间的动态响应关 系, 本文基于 MATLAB 软件并采用互相关函数来分析不同水文要素之间的联系. 互相关函数不仅可以反映 不同信号或要素之间的相关程度,还可以通过滞后距等时间信息来指示信号或要素之间的响应,该方法已 广泛应用于气象、水文、物理等不同的学科领域,其数学表达式为 ${ }^{[22]}$ :

$$
\begin{gathered}
C_{x y}(k)= \begin{cases}\frac{1}{L} \sum_{t=1}^{L-k}\left(x_{t}-\bar{x}\right)\left(y_{t+k}-\bar{y}\right) & (k=0,1,2, \cdots) \\
\frac{1}{L} \sum_{t=1}^{L+k}\left(y_{t}-\bar{y}\right)\left(x_{t-k}-\bar{x}\right) & (k=0,-1,-2, \cdots)\end{cases} \\
r_{x y}(k)=\frac{C_{x y}(k)}{\sigma_{x} \cdot \sigma_{y}} \quad(k=0, \pm 1, \pm 2, \pm \cdots)
\end{gathered}
$$

式中, $k$ 表示滞后时间, $L$ 是时间序列的长度, $x_{t}$ 和 $y_{t}$ 分别表示输人和输出时间序列, $\bar{x}$ 和 $y$ 是输人和输出系列 的平均值, $r_{x y}(k)$ 是互相关函数, $\sigma_{x}$ 和 $\sigma_{y}$ 是时间序列的标准差, $C_{x y}(k)$ 表示互相关图. 如果 $C_{x y}(k)$ 的分布不对 称, 且在正滞后距情况下获得了 $r_{x y}(k)$ 最大值或最小值, 则输人信号会影响输出信号, 且响应时间是对应于 最大 $r_{x y}(k)$ 值的滞后时间 ${ }^{[22]}$. 此外, 本文还采用线性拟合方法来研究地下水位和地表水位之间的联系程度, 并探讨两者之间的相互关系.

\section{3 达西通量}

本文采用达西定律估算地表一地下水之间的交换通量. 达西定律即地下水流运动的能量守恒方程, 它是 描述地下水流运动速度的实验定律 ${ }^{[23]}$. 具体表达式为:

$$
q=-K \frac{\mathrm{d} h}{\mathrm{~d} l}
$$

式中, $q$ 为交换通量 $(\mathrm{m} / \mathrm{d}), K$ 为渗透系数 $(\mathrm{m} / \mathrm{d}), \mathrm{d} h / \mathrm{d} l$ 表示水力梯度 (无量纲).

在本研究中, 水力梯度根据修水或碟形湖到地下水监测点的中心位置 $(\mathrm{d} l)$ 来进行近似估算. 对于渗透 系数, 文中通过野外现场坚管法来进行测定, 该方法已在美国和国内不同地区得到颇为广泛的应用. 在研究 区的河流和湖泊水体附近,垂直于河流和湖泊, 共设计 2 组实验, 6 个坚管, 将直径 $5 \mathrm{~cm}$ 的 PVC 管子垂直打 人沉积物一定深度 (管中沉积物深度大约为 $50 \sim 60 \mathrm{~cm}$ ), 然后向管中一次性注水, 因为管中水头高于周边河 湖水位, PVC 管内水头开始自然下降, 通过记录不同时刻管内的水头下降值, 计算相应的渗透系数 (如图 4 现场照片所示), 具体原理和计算方法请参照 Chen 的方法 ${ }^{[24]}$. 基于现场试验和计算, 获取多个点位渗透系 数的取值变化为 $2.3 \times 10^{-6} \sim 7.1 \times 10^{-3} \mathrm{~m} / \mathrm{s}$. 结合图 3 和表 1 结果的辅助分析, 可认为碟形湖湿地沉积物在 15 $\mathrm{m}$ 深度内近似呈均质分布, 坚管法的试验结果可用来综合反映研究区的渗透系数, 由此估计细粉砂和黏土 组成的湖床沉积物的平均渗透系数为 $2.5 \times 10^{-6} \mathrm{~m} / \mathrm{s}$, 砂砾和砾石组成的河床沉积物的平均渗透系数为 $6.0 \times$ 
$10^{-3} \mathrm{~m} / \mathrm{s}$, 表明碟形湖的湖床渗透性能要明显弱于河床.
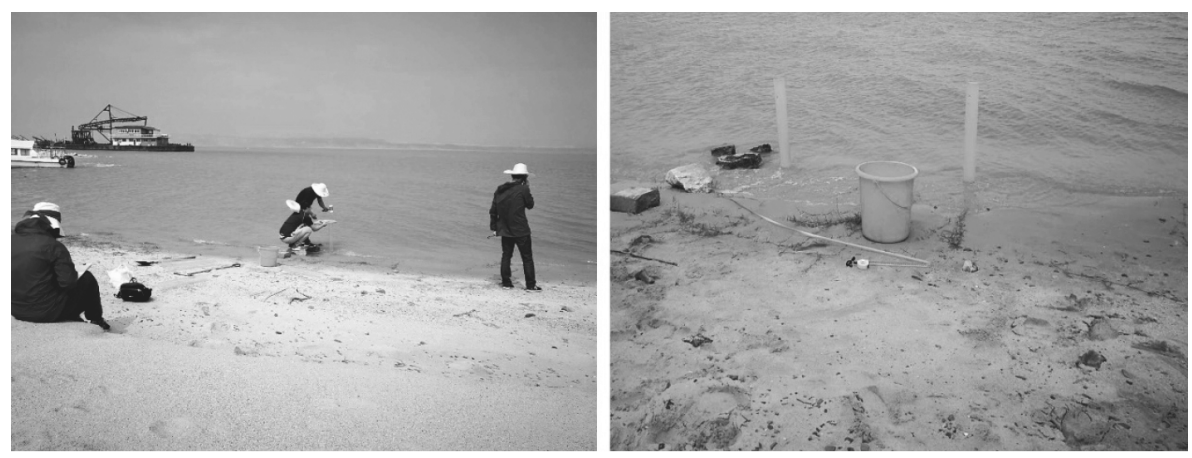

图 4 野外现场坚管法测定研究区沉积物渗透系数

Fig.4 Field measurement of the hydraulic conductivity in the study area using straight and l-shaped standpipes

\section{3 结果与分析}

\section{1 地表一地下水文特征与过程分析}

图 5 反映了碟形湖湿地洲滩地下水和主要地表水体的水位动态变化过程. 可以发现,地下水位与河流 水位、碟形湖水位具有相似的年内动态变化规律, 但河流水文变化对洲滩地下水位的影响要更为显著 $(P<$ $0.05)$. 这是由于河流为其邻近的碟形湖湿地提供了能量和脉冲的输人, 很大程度上增强了地下水的动力学 进程 ${ }^{[18]}$. 一般来说, 在春季较为湿润的月份,受降雨量增加的影响,地下水位和河流水位迅速上升,进人夏 季, 由于受到不断增强的地表水文连通性影响,地下水、河流和碟形湖的水位变化几乎保持同步,水位高程 基本介于 $15 \sim 19 \mathrm{~m}$ 之间 (图 5 灰色虚线之间), 可以推测地下水与地表水之间很有可能存在着季节性水力联 系. 在秋、冬季节, 虽然碟形湖的水位变化幅度相对较小 $(<0.4 \mathrm{~m})$, 但地下水位与河流水位均呈现明显下降 趋势. 换句话说, 同碟形湖水位变化相比, 河流水位与大多数监测点地下水位的下降速度更快 (例如 9 月). 需要说明的是, 在秋、冬季节的某些时段, 观测到地下水位迅速上涨且变幅可达 $3 \mathrm{~m}$ (图 5 黑色线框所示), 这 是因为在没有特大降雨事件的正常气候变化条件下 (图 2), 河道上游水库泄水等人为因素很有可能导致了 修水流量的急剧增加, 进而影响了周边湿地系统的地下水文情势. 仅从水文变化规律来看, 洲滩地下水位明 显低于碟形湖水位,但总体上略高于修河水位.

为捕捉研究区地下水运动的一般特征, 本文通过水位差 (代替水力梯度) 来评估碟形湖湿地系统地表一 地下水之间的水力交互关系. 结合图 4 可知, 地表水和地下水在秋、冬季, 两者之间的水位差可达 $4 \mathrm{~m}$, 可见 地下水与碟形湖、河流等地表水体之间存在很大程度上的水力交互作用. 通过各个监测点水位高程的比较 可得, 区域地下水流向在河流一洲滩湿地一碟形湖系统是高度动态、尤为复杂的. 绝大多数时期, 碟形湖水位 高于地下水位, 表明碟形湖很有可能补给洲滩湿地的地下水, 因水力梯度作用, 地下水总体上向邻近河流进 行排泄(图 5).

\section{2 地表一地下水交互关系与响应分析}

为进一步探究研究区地表一地下水之间的交互关系, 图 6 基于统计分析来解析蚌湖、沙湖、河流等地表 水体与洲滩地下水的水力联系. 线性拟合结果表明, 洲滩地下水位与蚌湖水位 ( $\mathrm{BW} ; R^{2}=0.68 \sim 0.89$ ) 的相关 性要高于其与沙湖水位的相关性 $\left(\mathrm{SW} ; R^{2}=0.39 \sim 0.72\right)$. 与碟形湖相比, 洲滩地下水位 $(\mathrm{GW} 1 \sim \mathrm{GW} 6)$ 与修水 水位 $(\mathrm{RW})$ 的统计学关系更为密切, 相关系数 $R^{2}$ 为 $0.93 \sim 0.98$ (图 6). 由此表明,洪泛区的河流水文情势对 洲滩地下水系统起着更为重要的影响作用. 互相关分析结果表明, 大部分监测点的地下水位与河流水位的 互相关系数 $R^{2}$ 在 $0.97 \sim 0.99$ 之间 (GW3 除外), 滞后或响应时间基本小于 $2 \mathrm{~d}$, 然而所有监测点的地下水位 与碟形湖水位之间的互相关系数 $R^{2}$ 小于 0.5 , 表明两者相关性较弱, 且存在着非常缓慢的时间响应 (图 7). 总结得出, 河流水文情势是控制洪泛湿地及其地下水系统的主要因素, 这与图 6 所得结论基本一致. 上述发 


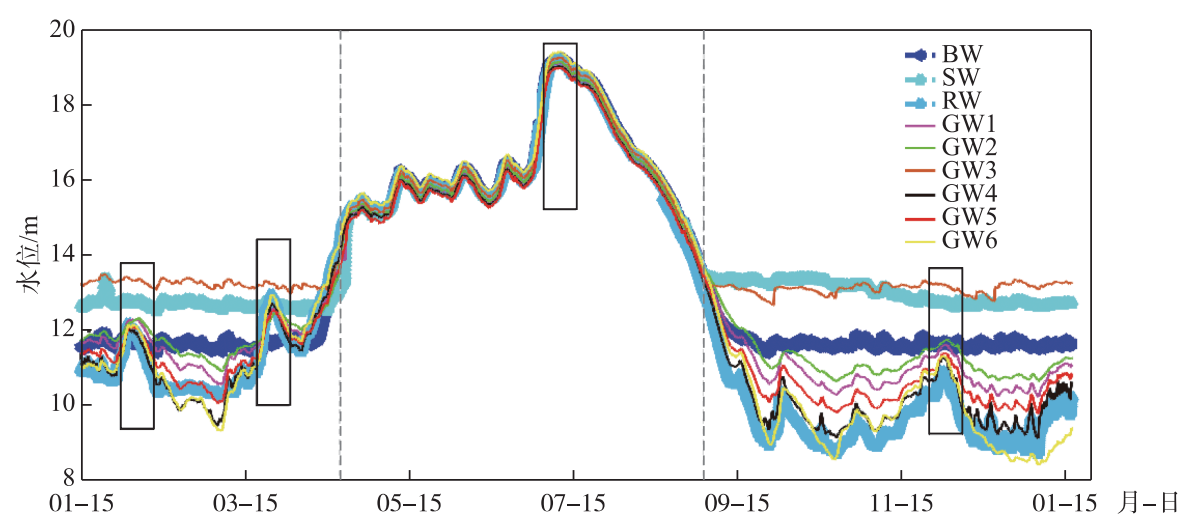

图 5 2016-2017 年鄱阳湖典型洪泛湿地系统地表水位和地下水位变化过程

Fig.5 Water level time series for surface water and groundwater in the Lake Poyang floodplain wetland from 2016 to 2017

现的主要原因可归结为如下两方面:一方面,因自身地形地貌特点,造成了碟形湖、地下水、河水之间的水位 差异, 这也完全符合地形变化对地下水运动的主要影响这一普遍认可结论; 另一方面, 对于鄱阳湖洪泛湿地 系统, 因碟形湖底部的弱透水性阻滞了其与地下水之间的水力交互, 河流作为研究区的一个重要驱动力和 强渗透性在促进地下水系统的动态方面发挥了强大的脉冲作用.

(a) GW1
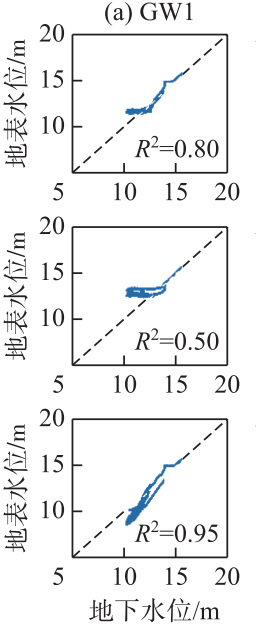

(b) GW2
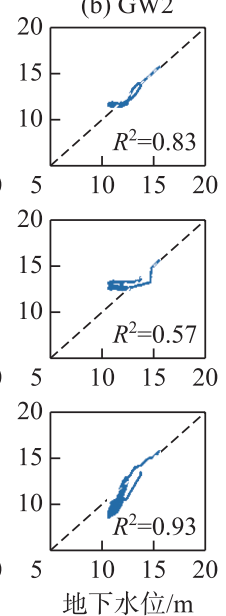

(c) GW3
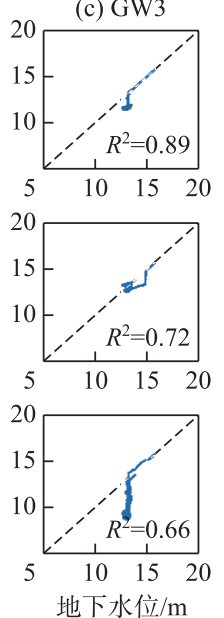

(d) GW4
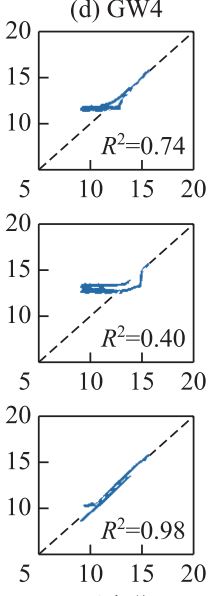

地下水位 $/ \mathrm{m}$ (e) GW5
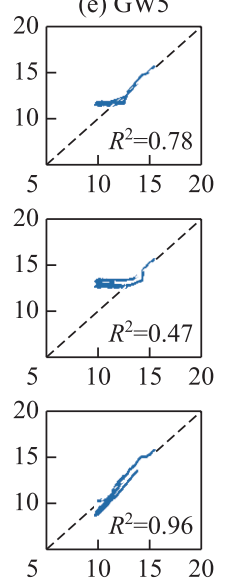

地下水位 $/ \mathrm{m}$ (f) GW6
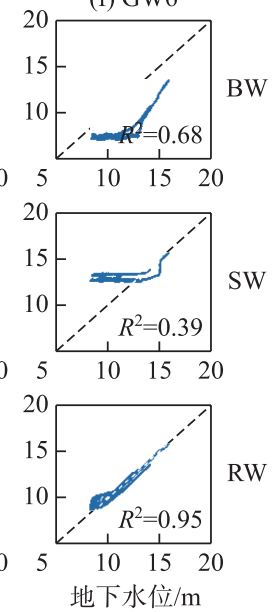

图 6 研究区地下水位 $(\mathrm{a} \sim \mathrm{f})$ 和地表水位 $(\mathrm{BW} 、 \mathrm{SW}$ 和 $\mathrm{RW})$ 的拟合关系分析

Fig.6 Fitting analysis for $(a-f)$ groundwater and surface water levels of $B W$, SW and RW with the $1: 1$ line and the correlation coefficient $R^{2}$

\section{3 地表一地下水交换通量估算与动态转化}

图 8 呈现了基于达西定律估算的碟形湖湿地系统地表水与地下水之间的交换通量动态变化. 一般来 说,河流、碟形湖与洲滩地下水之间相互作用的交换通量主要取决于水力梯度变化和地质条件差异 (图 8a). 从日尺度变化过程来看, 修水河流一地下水之间的日交换通量呈高度动态的变化特征, 然而碟形湖一地下水 之间的日交换通量变化则相对平稳. 总体上,该系统的地表一地下水日交换通量在 1-4 月和 9-12 月的波 动较为明显, 尤其是每年的 9-10月, 修水河流明显受到洲滩地下水的补给 ( RW-GW; 正值), 且两者之间侧 向交换通量较大, 最大补给强度可达 $0.4 \mathrm{~m} / \mathrm{d}$ (图 $8 \mathrm{~b}$ ). 在年内 5-8 月份, 本次估算结果得出地表一地下水之 

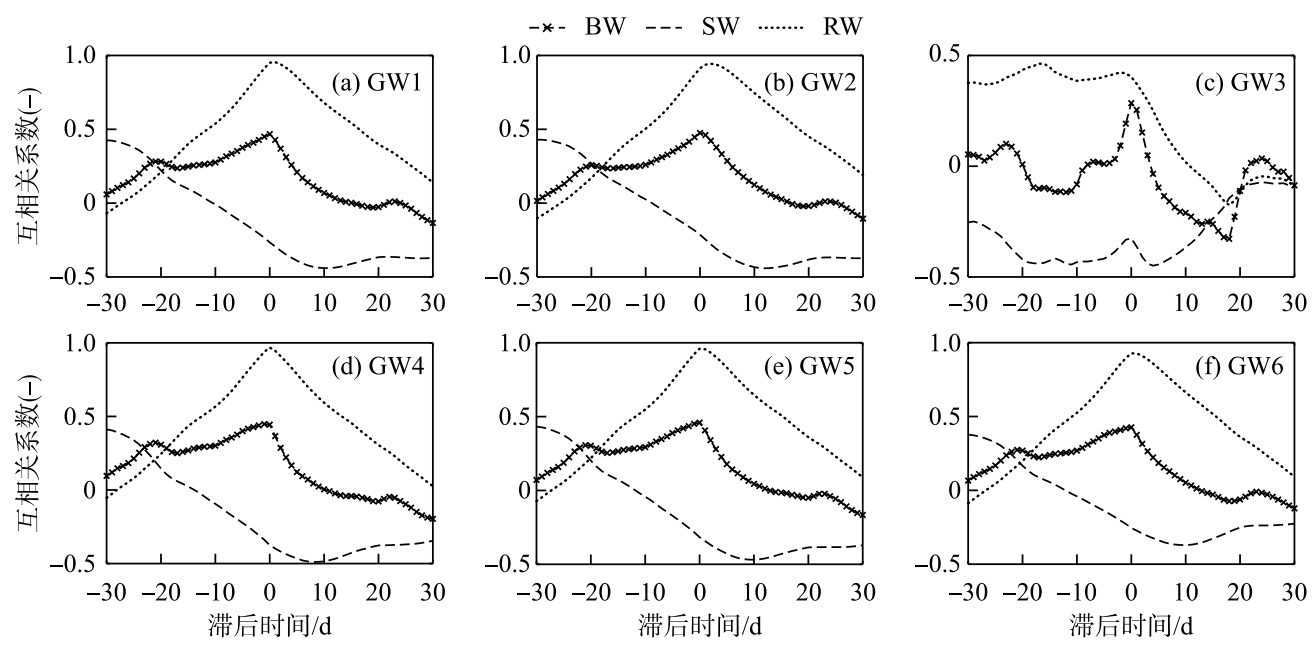

图 7 研究区地下水位 $(\mathrm{a} \sim \mathrm{f})$ 和地表水位 $(\mathrm{BW} 、 \mathrm{SW}$ 和 $\mathrm{RW})$ 的互相关分析

(互相关系数的最大值对应于响应时间)

Fig.7 Cross-correlation function for $(\mathrm{a}-\mathrm{f})$ wetland groundwater level responses to the water level of BW, SW and RW (the maximum cross-correlation coefficient corresponds to the time lag)

间的交换通量在 $0 \mathrm{~m} / \mathrm{d}$ 附近波动 (图 $8 \mathrm{~b}$ ), 这是由于碟形湖湿地被湖水淹没时间长达近 3 个月之久, 碟形湖 湿地的地下水系统近似呈饱和状态, 加上长江高洪水位的顶托作用,该时期湖水和地下水流均受到严重阻 滞作用而体现出流动性较差 ${ }^{[17,19]}$, 可推测该时期地表一地下水之间的总体交互作用比较微弱. 在 3-4 月期 间,观察到修水河流补给地下水的情况发生,但补给通量基本小于 $0.2 \mathrm{~m} / \mathrm{d}$. 此外,两个碟形湖与地下水之间 (BW-GW 和 SW-GW) 交换通量呈现年内高度一致的变化态势, 主要体现在碟形湖补给洲滩地下水系统, 交 换通量约小于 $0.1 \mathrm{~m} / \mathrm{d}$.

由图 8c 可见, 蚌湖一地下水 (BW-GW)、沙湖一地下水 (SW-GW)、河流一地下水 ( RW-GW) 之间的年累积 交换通量分别为 7.5、12.6 和 $48.2 \mathrm{~m} / \mathrm{a}$, 其中河流一地下水的累积交换通量分别约是蚌湖一地下水和沙湖一地 下水的 7 倍和 4 倍, 进一步证实了河流水文情势对洪泛区系统的重要影响作用. 除了可见河流一地下水累积 交换通量 ( SW-GW) 明显大于碟形湖一地下水之外 (BW-GW 和 SW-GW), 还发现秋、冬季的累积交换通量明 显大于春、夏季,取决于季节条件变化下地表和地下水文情势的动态与差异.

\section{4 讨论与展望}

地表一地下水之间的联系与转化在洪泛区湿地系统中表现得动态且复杂, 两者通过水力交互作用进人 湿地系统, 但水流总体上运动缓慢, 滞留时间较长, 这对湿地生物地球化学循环过程起着十分重要的影 响 ${ }^{[25]}$. 鄱阳湖正面临着气候变化和人类活动的双重干扰, 例如湖区水资源利用和大坝、水库的建设运行等, 加上湖水一地下水之间的频繁水力交互, 这些因素均会对湿地系统的地表一地下水相互作用带来显著影 响 ${ }^{[4,26]}$. 以本文碟形湖湿地附近的修水河流为例, 由于距离研究区约 $8 \mathrm{~km}$ 的上游水闸的人工调控, 使得修水 河流水位遭受了明显的扰动, 改变了河流与周边湿地之间的水力梯度, 无疑会促进河流一地下水之间的交互 作用与动态转化. 值得一提的是, 为了缓解湖区枯水与干旱问题, 江西省拟在鄱阳湖人江水道处建设鄱阳湖 水利枢纽工程 ${ }^{[27]}$. 鄱阳湖拟建水利枢纽的利弊和博亦已持续多年, 总体上, 水利枢纽将抬高鄱阳湖低枯水 位, 可短时间内有效缓解湖区干旱缺水问题. 但水利枢纽的建设, 无疑在很大程度上扰动了湖泊水文水动力 条件,会导致不同湖域水深、流速和温度变化 ${ }^{[19]}$. 水动力要素的改变无疑会干扰碟形湖湿地系统内的地表一 地下水相互作用, 从而影响湿地生态系统的健康维系. 近 10 年, 由于气候变化和人类活动的影响, 鄱阳湖低 水位频现 ${ }^{[28]}$. 在未来变化气候条件下, 鄱阳湖水位很有可能呈现 “洪季偏洪, 枯季偏枯” 的变化趋势 ${ }^{[29]}$, 可 能会对地表一地下水之间的动态转化以及水环境质量等产生不可估计的影响. 结合本文研究结果, 不管是气 


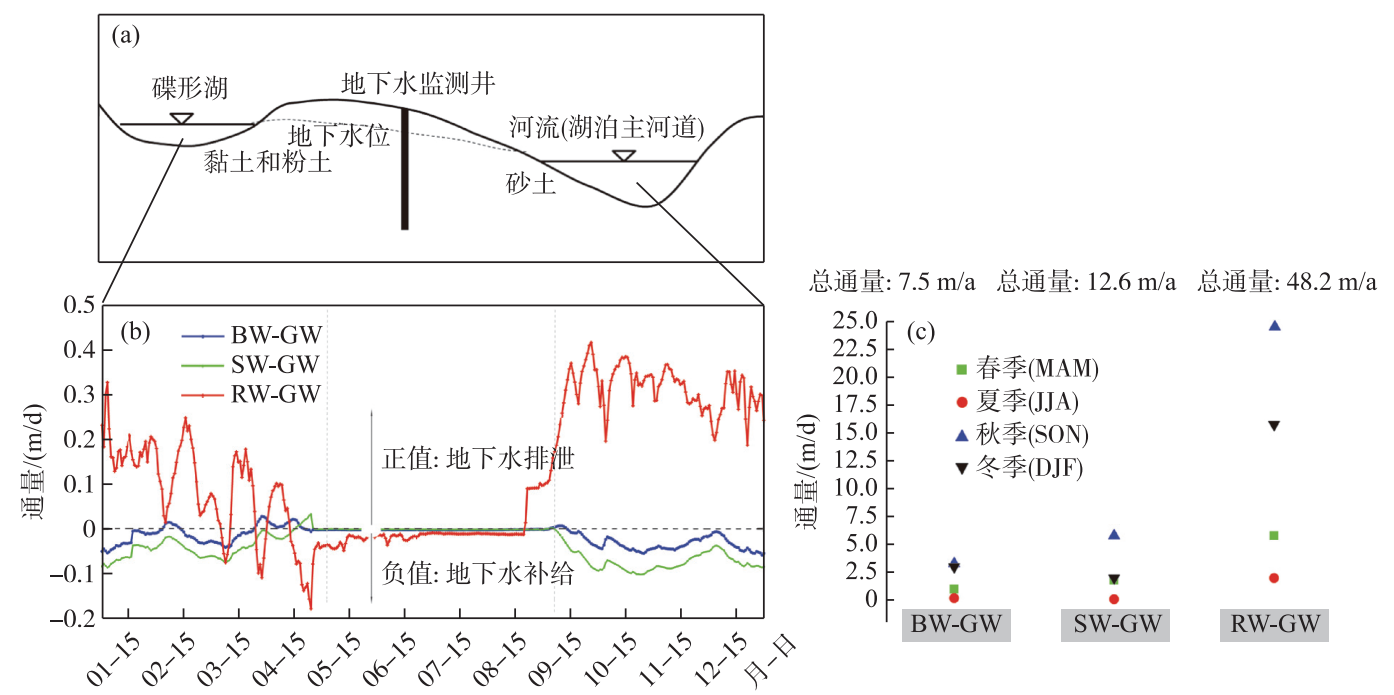

图 8 碟形湖湿地系统概念示意图 (a) 和地表一地下水交换通量的动态转化 $(\mathrm{b} \sim \mathrm{c}$ )

Fig.8 Conceptual diagram of the seasonal lake-wetland system (a) and estimated Darcy flux rate using the surface water levels (BW, SW and RW) and groundwater levels (averaged over GW1-GW6) (b-c)

候变化还是强人类活动的干扰, 建议应加强对秋、冬季湿地地下水位监测与评估, 比如江湖关系变化对鄱阳 湖湿地系统地下水的影响方式与程度? 拟建水利枢纽工程到底对地下水系统带来多大影响或贡献? 未来 气候变化是否会进一步加剧地下水资源量的转化? 这些变化环境下的地下水问题对生态系统带来多大影 响与反馈? 目前这方面研究几乎属于空白,理论和实践上均未获得足够重视.

对于湿地系统, 国内外在地表一地下水转化关系以及交换量等方面取得了大量研究成果. 例如, Ludwig 和 Hession ${ }^{[30]}$ 通过基础观测数据探明了河流水情变化对 Chesapeake 洪泛湿地系统地下水具有主控作用, 研 究发现季节性地下水位变化对湿地演化等具有不可忽视的影响. Rahman 等 ${ }^{[31]}$ 采用 SWATrw 模型探讨了印 度/孟加拉国 Barak-Kushiyara 洪泛湿地地表一地下水之间的交互作用, 发现河流水文对地下水的补给以及湿 地水量的维持起主要作用. Whittecar 等 ${ }^{[32]}$ 以地下水补给涵养的美国弗吉尼亚湿地为研究区, 基于水量平衡 方法估算了地下水对湿地的补给量, 认为地下水位波动对湿地系统水均衡变化具有重要影响. 虽然上述湿 地系统与鄱阳湖洪泛湿地存在诸多差异, 但均得出了季节性河湖水文情势是导致湿地地下水变化的主要作 用因素. 虽然碟形湖是本文研究区内的重要水体, 考虑到碟形湖水位不仅受到河流来水影响, 其自身变化也 相对稳定, 加上湖床的弱渗透性, 其对周边地下水系统的贡献度可能有限. 根据湿地地表一地下水之间的转 化关系以及饱和一非饱和流理论, Jolly 等 ${ }^{[33]}$ 定义了非饱和流一补给型湿地、饱和流一补给型湿地、饱和流一排 泄型湿地以及饱和流一贯穿型湿地. 例如, 美国 North Dakota 湿地自然条件下为贯穿型湿地, 干旱则导致湿 地持续补给周边地下水, 接受集中降水后则转变为排泄型湿地 ${ }^{[34]}$. 结合本文研究, 补给和排泄仍是鄱阳湖 湿地的主要转化方式, 但补排强度存在明显差异, 后续还应加强非饱和流的监测与评估.

本文利用碟形湖湿地有限监测点位开展了地表一地下水交互作用研究, 目前的湿地观测仅限于洲滩湿 地的浅层地下水, 深层地下水的流动也会对湿地系统的水文过程带来难以想象的影响, 但详尽的地下水监 测与分析也极具挑战性. 下一步工作需要充分利用目前已有基础观测资料, 构建洪泛湿地的地表一地下水联 合模型, 提升对地表一地下水转化机理与动力学机制的认识, 并以此耦合湿地生态模型, 真正意义上探求湿 地生态水文的互馈作用与效应. 本文实际上是针对碟形湖湿地系统的地表一地下水交换的侧向通量加以分 析, 并没有考虑两者之间的垂向联系与交互作用. 通过地表水体及其底层沉积物的温度示踪为垂直通量的 合理估算提供了一种有效技术方法 ${ }^{[5]}$. 本研究涉及的碟形湖湿地系统, 蚌湖、沙湖和修水等主要地表水体温 度变化范围为 $-3 \sim 32^{\circ} \mathrm{C}$, 地下水温度变化范围为 $14 \sim 19.8^{\circ} \mathrm{C}$ ( 图 9a), 不难发现, 相对于地表水体, 地下水的 
温度变化要相对稳定, 且与地表水体温度存在较大的季节性差异. 然而, 上述观测井中的地下水温度还无法 用来准确反映湖床/河床沉积物的真实温度 (图 9b). 因此, 后续工作可以考虑采用温度示踪法开展鄱阳湖 洪泛系统中地表一地下水垂向交换通量研究. 总之, 未来可结合野外观测、数学模型和示踪等技术手段,依托 多方法耦合的定量研究, 从当前的局地尺度拓展到整个湖区, 深人分析鄱阳湖洪泛区湿地的地表一地下水转 化问题.
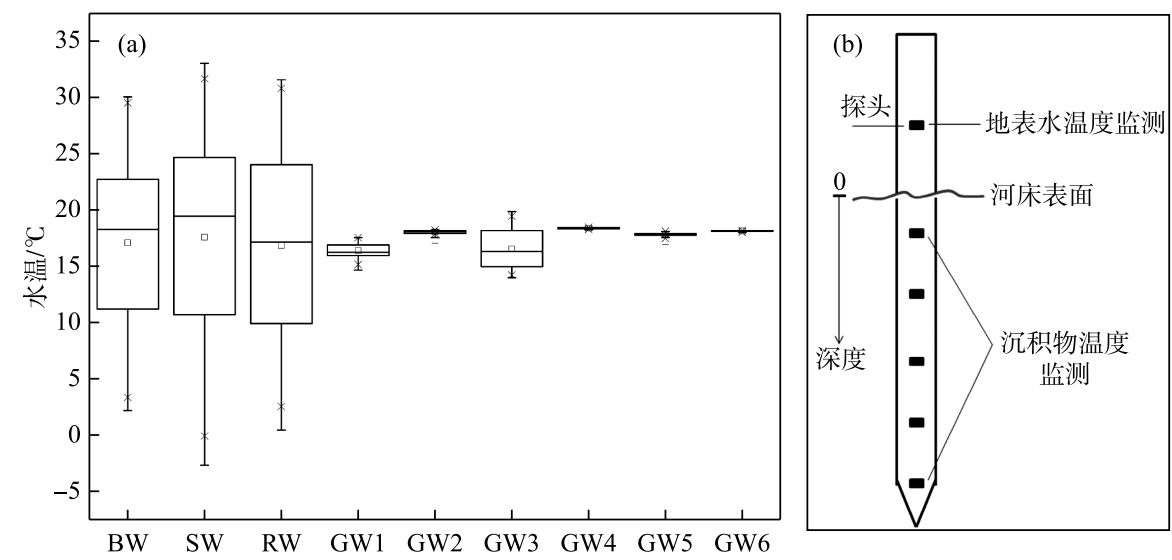

图 9 碟形湖湿地系统地表一地下水温度变化序列 (a) 和基于温度序列的示踪原理(b)

Fig.9 Water temperature time series for surface water and groundwater in the Lake Poyang floodplain wetland during the study period (a) and basic theory for the thermal tracer method (b)

\section{4 结论}

鄱阳湖洪泛区湿地具有很强的地表和地下蓄水能力, 地表一地下水交互研究对湖泊湿地水文和生态功 能具有切实意义. 本文鉴于鄱阳湖洪泛区湿地的重要性以及地下水研究的相对薄弱性, 主要利用原位综合 观测、野外试验、统计分析和达西定律等技术方法,探究鄱阳湖洪泛区碟形湖湿地系统的地表一地下水文特 征、交互作用及其转化通量. 结果表明,受鄱阳湖地形地貌等条件影响,研究区洲滩地下水位明显低于碟形 湖水位, 但总体上略高于周边河流水位, 但洲滩地下水与河流、碟形湖等地表水体具有相似的水位变化动 态, 表明地表水和地下水之间可能具有密切的水力联系. 统计分析进一步表明,在控制洪泛洲滩地下水动态 方面, 河流水文情势变化对地下水系统的影响作用要明显强于碟形湖. 平均意义上,研究区洲滩地下水对河 流的补给通量及河流对地下水的补给通量分别约为 0.4 和 $0.2 \mathrm{~m} / \mathrm{d}$, 总体上碟形湖补给周边地下水系统, 且 两者之间的交换通量基本小于 $0.1 \mathrm{~m} / \mathrm{d}$. 在季节尺度上, 研究区地表一地下水之间的年累积交换通量变化范 围为 $7.5 \sim 48.2 \mathrm{~m} / \mathrm{a}$, 河流一地下水的累积交换通量约是碟形湖一地下水交换通量的 $4 \sim 7$ 倍, 秋、冬季的累积 交换通量要明显大于春、夏季. 研究结果可为河湖湿地水资源管理、水环境治理及生态环境保护等方面提供 科学支撑.

致谢: 文中地下水位资料主要来自中国科学院南京地理与湖泊研究所张奇研究员团队在吴城国家级自然保 护区的长期监测数据, 特此致谢.

\section{5 参考文献}

[ 1 ] Winter TC. Relation of streams, lakes, and wetlands to groundwater flow systems. Hydrogeology Journal, 1999, 7( 1): 28-45. DOI: $10.1007 / \mathrm{s} 100400050178$.

[ 2 ] Karan S, Sebok E, Engesgaard P. Air/water/sediment temperature contrasts in small streams to identify groundwater seepage locations. Hydrological Processes, 2017, 31(6) : 1258-1270. DOI: 10.1002/hyp.11094.

[ 3 ] Kaandorp VP, Molina-Navarro E, Andersen HE et al. A conceptual model for the analysis of multi-stressors in linked 
groundwater-surface water systems. Science of the Total Environment, 2018, 627: 880-895. DOI: 10. 1016/j. scitotenv. 2018.01.259.

[ 4 ] Hutchins MG, Abesser C, Prudhomme C et al. Combined impacts of future land-use and climate stressors on water resources and quality in groundwater and surface waterbodies of the upper Thames river basin, UK. Science of the Total Environment, 2018, 631/632: 962-986. DOI: 10.1016/j.scitotenv.2018.03.052.

[ 5 ] Keery J, Binley A, Crook N et al. Temporal and spatial variability of groundwater-surface water fluxes: Development and application of an analytical method using temperature time series. Journal of Hydrology, 2007, 336(1/2) : 1-16. DOI: 10. 1016/j.jhydrol.2006.12.003.

[ 6 ] Qu WJ, Li HL, Huang H et al. Seawater-groundwater exchange and nutrients carried by submarine groundwater discharge in different types of wetlands at Jiaozhou Bay, China. Journal of Hydrology, 2017, 555: 185-197. DOI: 10.1016/j. jhydrol.2017.10.014.

[ 7 ] Irvine DJ, Lautz LK, Briggs MA et al. Experimental evaluation of the applicability of phase, amplitude, and combined methods to determine water flux and thermal diffusivity from temperature time series using VFLUX 2. Journal of Hydrology, 2015, 531: 728-737. DOI: 10.1016/j.jhydrol.2015.10.054.

[ 8 ] Jutebring SE, Johansson E, Sjöberg Y et al. Groundwater-surface water interactions across scales in a boreal landscape investigated using a numerical modelling approach. Journal of Hydrology, 2018, 560: 184-201. DOI: 10.1016/j.jhydrol. 2018.03.011.

[ 9 ] Jin K, Rao WB, Tan HB et al. H-O isotopic and chemical characteristics of a precipitation-lake water-groundwater system in a desert area. Journal of Hydrology, 2018, 559: 848-860. DOI: 10.1016/j.jhydrol.2018.03.005.

[10] McCallum AM, Andersen MS, Rau GC et al. River-aquifer interactions in a semiarid environment investigated using point and reach measurements. Water Resources Research, 2014, 50(4) : 2815-2829. DOI: 10.1002/2012wr012922.

[11] Cremeans MM, Devlin JF, McKnight US et al. Application of new point measurement device to quantify groundwater-surface water interactions. Journal of Contaminant Hydrology, 2018, 211: 85-93. DOI: 10.1016/j.jconhyd.2018.03.010.

[12] Turner JV, Townley LR. Determination of groundwater flow-through regimes of shallow lakes and wetlands from numerical analysis of stable isotope and chloride tracer distribution patterns. Journal of Hydrology, 2006, 320(3/4) : 451-483. DOI: 10.1016/j.jhydrol.2005.07.050.

[13] Yang WJ, You QH, Fang N et al. Assessment of wetland health status of Poyang Lake using vegetation-based indices of biotic integrity. Ecological Indicators, 2018, 90: 79-89. DOI: 10.1016/j.ecolind.2017.12.056.

[14] Sun CZ, Zhen L, Giashuddin Miah M. Comparison of the ecosystem services provided by China's Poyang Lake wetland and Bangladesh's Tanguar Haor wetland. Ecosystem Services, 2017, 26: 411-421. DOI: 10.1016/j.ecoser.2017.02.010.

[15] Li YY, Yuan DK, Lin BL et al. A fully coupled depth-integrated model for surface water and groundwater flows. Journal of Hydrology, 2016, 542: 172-184. DOI: 10.1016/j.jhydrol.2016.08.060.

[16] Xu XL, Zhang Q, Tan ZQ et al. Effects of water-table depth and soil moisture on plant biomass, diversity, and distribution at a seasonally flooded wetland of Poyang Lake, China. Chinese Geographical Science, 2015, 25(6) : 739-756. DOI: 10. 1007/s11769-015-0774-x.

[17] Li YL, Yao J, Zhao GZ et al. Evidences of hydraulic relationships between groundwater and lake water across the large floodplain wetland of Poyang Lake, China. Water Supply, 2018, 18(2) : 698-712. DOI: 10.2166/ws.2017.150.

[18] Zhang X, Xiao Y, Wan H et al. Using stable hydrogen and oxygen isotopes to study water movement in soil-plant-atmosphere continuum at Poyang Lake wetland, China. Wetlands Ecology and Management, 2017, 25(2) : 221-234. DOI: 10. 1007/s11273-016-9511-1.

[19] Li YL, Zhang Q, Werner AD et al. The influence of river-to-lake backflow on the hydrodynamics of a large floodplain lake system (Poyang Lake, China). Hydrological Processes, 2017, 31(1) : 117-132. DOI: 10.1002/hyp.10979.

[20] Hu ZP, Zhang ZF, Liu YZ et al. The function and significance of the shallow-lakes in the Poyang Lake wetland ecosystem. Jiangxi Hydraulic Science \& Technology, 2015, 41(5): 317-323. [胡振鹏, 张祖芳, 刘以珍等. 碟形湖在鄱阳湖湿地 生态系统的作用和意义. 江西水利科技, 2015, 41(5): 317-323.]

[21] Seasonal water exchanges between China's Poyang Lake and its saucer-shaped depressions on river deltas. Water, 2017, 9 (11) : 884. DOI: 10.3390/w9110884.

[22] Ziegel ER, Box G, Jenkins G et al. Time series analysis, forecasting, and control. Technometrics, 1995, 37(2): 238. 
DOI: $10.2307 / 1269640$.

[23] Freeze RA, Cherry JA eds. Groundwater. Englewood Cliffs: Prentice-Hall, 1979: 604.

[24] Chen XH. Measurement of streambed hydraulic conductivity and its anisotropy. Environmental Geology, 2000, 39(12): 1317-1324. DOI: 10.1007/s002540000172.

[25] Gu C, Anderson W, Maggi F. Riparian biogeochemical hot moments induced by stream fluctuations. Water Resources Research, 2012, 48(9): W09546.

[26] Francis BA, Francis LK, Cardenas MB. Water table dynamics and groundwater-surface water interaction during filling and draining of a large fluvial island due to dam-induced river stage fluctuations. Water Resources Research, 2010, 46( 7 ) : W07513. DOI: 10.1029/2009WR008694.

[27] Jiao L. China. Scientists line up against dam that would alter protected wetlands. Science, 2009, 326(5952) : 508-509. DOI: $10.1126 /$ science.326_508.

[28] Zhang Q, Ye XC, Werner AD et al. An investigation of enhanced recessions in Poyang Lake: Comparison of Yangtze River and local catchment impacts. Journal of Hydrology, 2014, 517: 425-434. DOI: 10.1016/j.jhydrol.2014.05.051.

[29] Ye XC, Zhang Q, Bai L et al. A modeling study of catchment discharge to Poyang Lake under future climate in China. Quaternary International, 2011, 244(2) : 221-229. DOI: 10.1016/j.quaint.2010.07.004.

[30] Ludwig AL, Hession WC. Groundwater influence on water budget of a small constructed floodplain wetland in the ridge and valley of Virginia, USA. Journal of Hydrology: Regional Studies, 2015, 4: 699-712. DOI: 10.1016/j.ejrh.2015.10.003.

[31] Rahman MM, Thompson JR, Flower RJ. An enhanced SWAT wetland module to quantify hydraulic interactions between ripariandepressional wetlands, rivers and aquifers. Environmental Modelling \& Software, 2016, 84: 263-289. DOI: 10. 1016/j.envsoft.2016.07.003.

[32] Whittecar GR, Dobbs KM, Stone SA et al. Use of the effective monthly recharge model to assess long-term water-level fluctuations in and around groundwater-dominated wetlands. Ecological Engineering, 2017, 99: 462-472. DOI: 10.1016/j. ecoleng.2016.11.038.

[33] Jolly ID, McEwan KL, Holland KL. A review of groundwater-surface water interactions in arid/semi-arid wetlands and the consequences of salinity for wetland ecology. Ecohydrology, 2008, 1(1) : 43-58. DOI: 10.1002/eco.6.

[34] Rosenberry DO, Winter TC. Dynamics of water-table fluctuations in an upland between two prairie-pothole wetlands in North Dakota. Journal of Hydrology, 1997, 191(1/2/3/4) : 266-289. DOI: 10.1016/S0022-1694(96) 03050-8. 